BANCA D'ITALIA

E U R O S I S T E M A

Questioni di Economia e Finanza

(Occasional Papers)

Alternative measures of underlying inflation in the euro area

by Cristina Conflitti 

13 BANCA D'ITALIA

E U ROS I S T E M A

\section{Questioni di Economia e Finanza}

(Occasional Papers)

Alternative measures of underlying inflation in the euro area

by Cristina Conflitti

Number 593 - December 2020 
The series Occasional Papers presents studies and documents on issues pertaining to the institutional tasks of the Bank of Italy and the Eurosystem. The Occasional Papers appear alongside the Working Papers series which are specifically aimed at providing original contributions to economic research.

The Occasional Papers include studies conducted within the Bank of Italy, sometimes in cooperation with the Eurosystem or other institutions. The views expressed in the studies are those of the authors and do not involve the responsibility of the institutions to which they belong.

The series is available online at www.bancaditalia.it.

ISSN $1972-6627$ (print)

ISSN 1972-6643 (online)

Printed by the Printing and Publishing Division of the Bank of Italy 


\title{
ALTERNATIVE MEASURES OF UNDERLYING INFLATION IN THE EURO AREA
}

\author{
by Cristina Conflitti*
}

\begin{abstract}
This paper proposes two measures of underlying inflation for the euro area as an alternative to the Harmonized Index of Consumer Prices excluding Food and Energy. The first measure, called the Core cycle measure, is constructed by using a Phillips curve model to distinguish disaggregated prices that respond to the economic cycle (procyclical), from those that do not (acyclical). The second measure, called the Common core measure, is constructed using a factor model to remove components that are subject to large or unusual price changes, which are unlikely to be related to the underlying trend of inflation because of their idiosyncratic nature. Each measure has its merits and shortcomings, suggesting that they should be taken together to assess inflation developments.
\end{abstract}

JEL Classification: C32, E31, E32.

Keywords: Core inflation, disaggregate consumer prices, dynamic factor model, Phillips curve.

DOI: $10.32057 / 0 . Q E F .2020 .589$

\section{Contents}

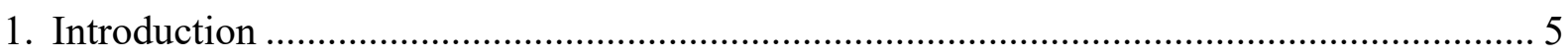

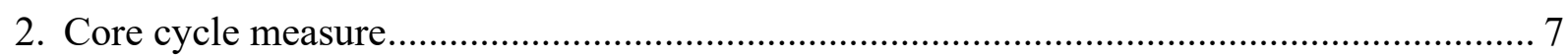

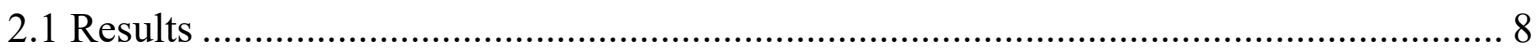

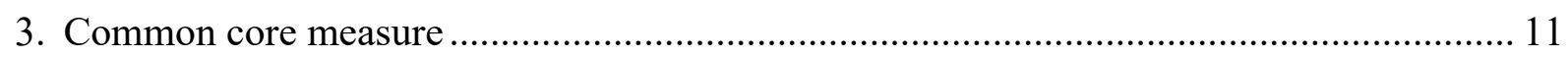

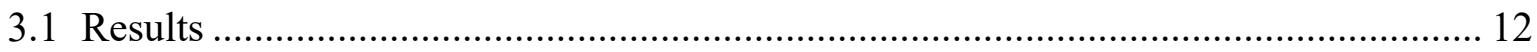

4. A comparison of measures of underlying inflation ....................................................... 16

4.1 How do alternative inflation measures perform in a Phillips curve setting?................ 18

4.2 Predictive accuracy of measures of underlying inflation .......................................... 19

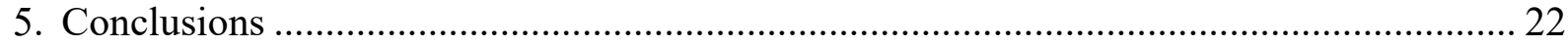

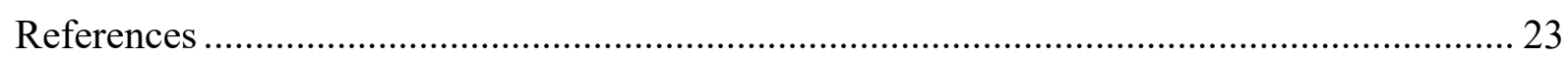

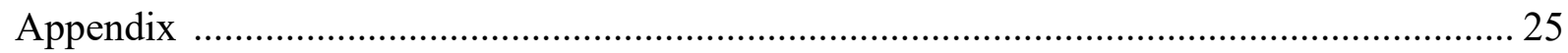

\footnotetext{
* Bank of Italy, Directorate General for Economics, Statistics and Research, Economic Outlook and Monetary Policy Department.
} 



\section{Introduction $^{*}$}

With price stability being their primary objective, the European Central Bank (ECB) and other central banks (see, for example, Yellen (2015) and Draghi (2019)) need to carefully assess the drivers of inflation in order to make the most appropriate policy decisions. The ECB has recently changed its forward guidance message, stressing the importance of relying (also) on underlying inflation dynamics when assessing the convergence of euro area inflation with the ECB's inflation target (Draghi (2019)). However, the Harmonized Index of Consumer Prices (HICP), the target variable for the ECB, includes volatile components whose fluctuations are beyond the reach of monetary policy. ${ }^{1}$ It is, therefore, crucial to construct alternative measures of inflation that would help to analyze underlying consumer price dynamics, to better distinguish transitory from persistent movements and, ultimately, to anticipate future developments in inflation more accurately.

One indicator of underlying inflation typically monitored by the ECB is core inflation, as released by Eurostat (HICPX), which removes a pre-specified list of items from the basket used for the estimation of overall inflation index, which are held to be particularly volatile, such as food and energy. Economists at the ECB have also developed other alternative inflation indicators that can be divided into three broad categories: (1) permanent exclusion measures, which, similarly to the HICPX, exclude items whose prices are particularly volatile from the headline index; ${ }^{2}(2)$ temporary exclusion measures, such as trimmed means and weighted medians, which exclude items that display the most extreme price changes ${ }^{3}$, and (3) frequency exclusion measures, such as Supercore and the Persistent and Common Component of Inflation (PCCI). Supercore is a measure of underlying inflation based on the sensitivity of the various components to business cycle conditions. The

\footnotetext{
*I would like to thank Antonio Maria Conti, Paolo Del Giovane, Matteo Luciani, Stefano Neri, Andrea Nobili, Sergio Santoro, Stefano Siviero, Alex Tagliabracci, Giordano Zevi and Roberta Zizza, for their useful comments on earlier drafts of the paper. Any errors are my responsibility.

${ }^{1}$ See Rostagno et al. (2019) 'Core and other measures of underlying inflation are important metrics to unearth the slow-moving trend driving price formation'.

${ }^{2}$ For example economists at the ECB track an HICPX index net of travel-related items, clothing and footwear.

${ }^{3}$ See also Ball and Mazumder (2019).
} 
PCCI, instead, captures the persistent and common component of inflation across euro area countries relying on a generalized dynamic factor model (ECB (2014),ECB (2018),OBrien (2018)). Similarly, economists at the Federal Reserve have developed alternative indicators of core inflation for the US, such as exclusion indexes and central-tendency statistical measures (Dallas FED Trimmed-Mean measure). In a recent work, Luciani (2020) disentangles changes in prices due to economy-wide (common) shocks from changes in prices due to idiosyncratic shocks.

In this article, we propose two measures of underlying inflation for the euro area. The first one exploits the Phillips curve setting to assess the reactiveness of disaggregated inflation to the developments in the real economy (Core cycle measure). In particular, we follow Mahedy and Shapiro (2017), who examine the factors keeping inflation low by analyzing inflation rates by spending category. They distinguish between categories whose inflation has historically shown a procyclical relationship with overall economic conditions, moving in tandem with the economic cycle, and categories whose inflation has been acyclical, that is, driven by category-specific developments that are independent of the state of the overall economy. The approach is thus similar to that exploited by the ECB to construct the Supercore index. The second measure is entirely data-driven and judgement-free (Common core measure). It is constructed by following the methodology in Conflitti and Luciani (2019) and in Luciani (2020), where the underlying trend in inflation is identified by removing components that are subject to large or unusual price changes, considering that such idiosyncratic changes are unlikely to be related to the underlying trend of overall and core inflation. The ECB uses a similar methodology to construct the PCCI index. We provide evidence that each measure has its merits and shortcomings. Therefore, we suggest that policymakers should monitor a wide range of underlying inflation measures for a comprehensive assessment of price dynamics.

The rest of the paper is organized as follows. Section 2 presents the Core cycle measure. 
Section 3 discusses the Common core measure. Section 4 provides a comparison of the available measures of underlying inflation. Section 5 concludes.

\section{Core cycle measure}

The traditional theory represented by the Phillips curve predicts a positive relationship between inflation and cyclical conditions. During recessions, characterized by high unemployment and an excess in the supply of goods, inflation should decline; during economic booms, when unemployment is low and aggregate demand exceeds supply, inflation should rise. Mahedy and Shapiro (2017), using data from 1985 through 2007 for the US, estimate the following backward-looking Phillips curve (PC) for each price category ${ }^{4}$ :

$$
y_{i, t}=\alpha y_{i, t-1}+\beta U G_{i, t-1}+u_{i, t}
$$

where $y_{i t}$ is the year-on-year $(y-o-y)$ growth rate of the price sub-index i and $U G$ is the unemployment gap (the gap between the unemployment rate and its long-term or natural rate). A price item is defined as procyclical if it features a negative and statistically significant relationship with the unemployment gap (i.e. $\beta<0$ ); if not, it is considered as acyclical. Mahedy and Shapiro (2017) find that procyclical and acyclical components have very different patterns. They also suggest that US core inflation was persistently low between 2011 and 2017, mainly due to the weakness of the acyclical component.

Using the methodology of Mahedy and Shapiro (2017), we estimate equation 1 for the euro area using quarterly data from 1997:Q1 to 2019:Q4. The dependent variable is the $y$-o$y$ growth rate of the price sub-index $i$ of the HICPX on the basis of the 2-digit E-COICOP

\footnotetext{
${ }^{4} \mathrm{~A}$ standard $\mathrm{PC}$ equation is employed in the knowledge that it could suffer from misspecification (for example, we neglect the role of expectations and other drivers). However, at this level of disaggregation, a simple specification is adequate for characterizing the relationship linking economic slack to price developments at the sectoral level.
} 
classification. ${ }^{5}$ The economic slack indicator is the unemployment gap. Our approach is conceptually similar to that used by the ECB to obtain the Supercore index (ECB (2018),OBrien (2018)), but we differ with several aspects. First, we use the unemployment gap instead of the output gap as an indicator of cyclical conditions. ${ }^{6}$ Second, the Supercore index is built using more granular information, namely the 3-digit ECOICOP classification of disaggregated price series. Third, the selection of the components to be included in the measure of underlying inflation is based on a different methodology. Specifically, in the ECB methodology an item contributes to the Supercore index if the inclusion of the output gap in its respective Phillips curve equation improves the accuracy of out-of-sample forecasts of such item at horizons of 1-4 quarters with respect to a simple autoregressive model. As a result of this approach, the set of items included in the Supercore changes on a monthly basis, clearly undermining the comparability of the latter's evolution over time. We instead select the list of items on the basis of the in-sample fitting of equation 1 over the whole sample, so that its composition is more stable over time. ${ }^{7}$

\section{$2.1 \quad$ Results}

About half of the $35 \mathrm{HICP}$ core components are sensitive to the unemployment gap (for more details see the Table in Appendix A.1); overall, they account for about 37 and 53 per cent of headline and core inflation, respectively. They include, among other things, recreational and cultural services, personal care, catering services, and furniture and fur-

\footnotetext{
${ }^{5}$ The data are not seasonally adjusted. We consider HICP components that are disaggregated in the 2-digit E-COICOP classification, i.e. $40 \mathrm{HICP}$ items (see the Appendix for the complete list), with the exception of Category 72 (operation of personal transport and equipment) which is further decomposed so as to exclude the 07.2.2 part of the index whose price depends on energy, i.e. fuels and lubricants for personal transport equipment. We have also replicated the analysis using the 3-digit E-COICOP classification, i.e. 93 HICP items that are the series used for the ECB Supercore index; robustness check's results are available upon request.

${ }^{6}$ We use the unemployment gap as a measure of slack because it has good forecasting properties for core inflation (see Conti (2020)) and to be fully coherent with the methodology of Mahedy and Shapiro (2017).

${ }^{7}$ We point out that using a different sample period the composition could change.
} 
nishings. The remaining HICP core components are acyclical (they account for about 33 per cent of headline inflation and for 47 per cent of core inflation) and include, among others, clothing, footwear, insurance, and social protection coverage. We then construct a procyclical indicator and an acyclical one by aggregating the corresponding components as categorized in the previous step (Figure 1). Their correlation is 0.32 on the entire sample period; being equal to 0.72 up to 2007 and it ended up being negative at -0.26 in 2014-2019. Focusing on the more recent years, the procyclical and acyclical inflation series both stood at values close to 1 per cent in 2014-2016; after that, the procyclical series increased up to 1.7 in 2018:Q3 before falling back to a low level, while the acyclical series has remained broadly flat since 2014, at around 1 per cent.

Figure 1: PROCYCliCAL, ACYCliCAL AND HICP CORE INFLATION IN THE EURO AREA (year-on-year changes; percentage points)

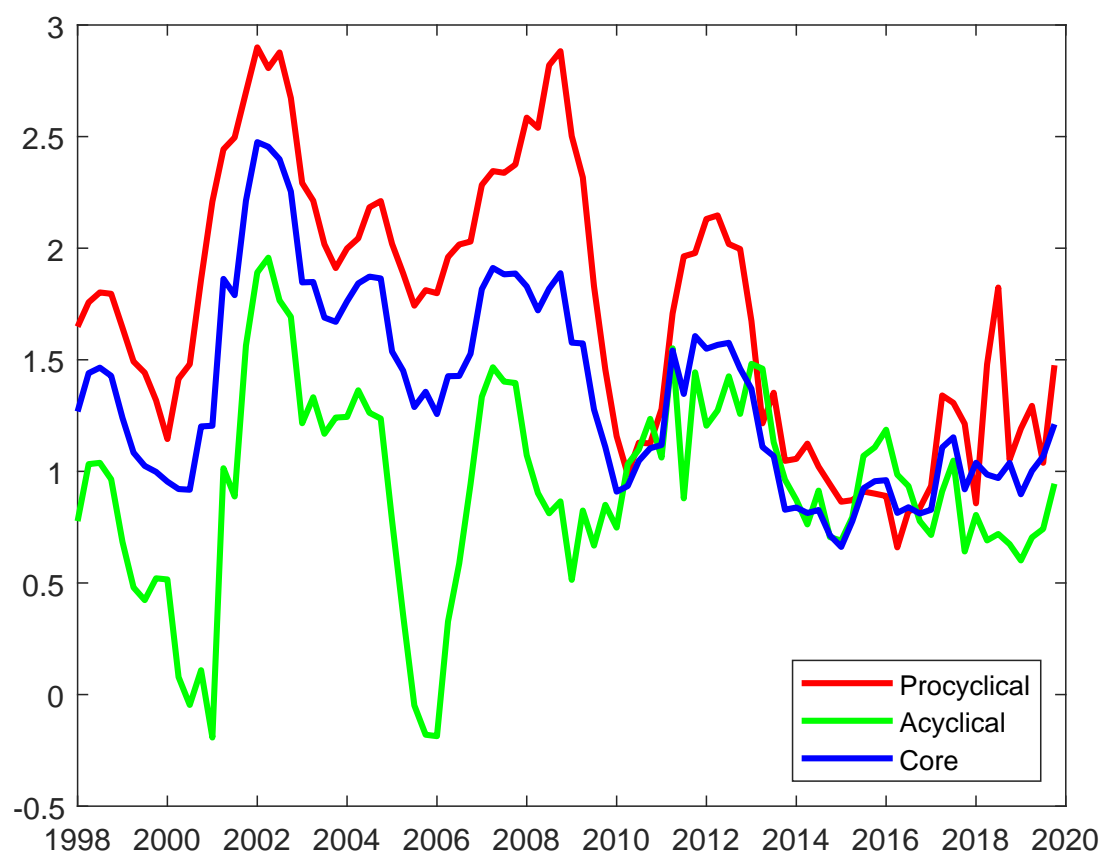

In Figure 2 we report the contributions of the two indicators to core inflation. They are calculated as the product between the inflation rate of each category and its annual weight 
in the overall index divided by the core weight in the overall index. ${ }^{8}$ Since the beginning of the low inflation period in late 2012, the contribution of the procyclical series has been stable at around 0.6 percentage points, showing a small increase up to 0.7 points in 2017 . On the other hand, the contribution of acyclical inflationhas not varied much between preand post-2012 (standing at 0.4 points on average). Procyclical inflation currently continues to contribute significantly less than its historical average level and does not display the gradual increase that had characterized the previous two cyclical peaks, in 2008 and 2012.

Figure 2: PROCYCLICAL, ACYCLICAL CONTRIBUTIONS TO CORE INFLATION (contributions to year-on-year changes; percentage points)

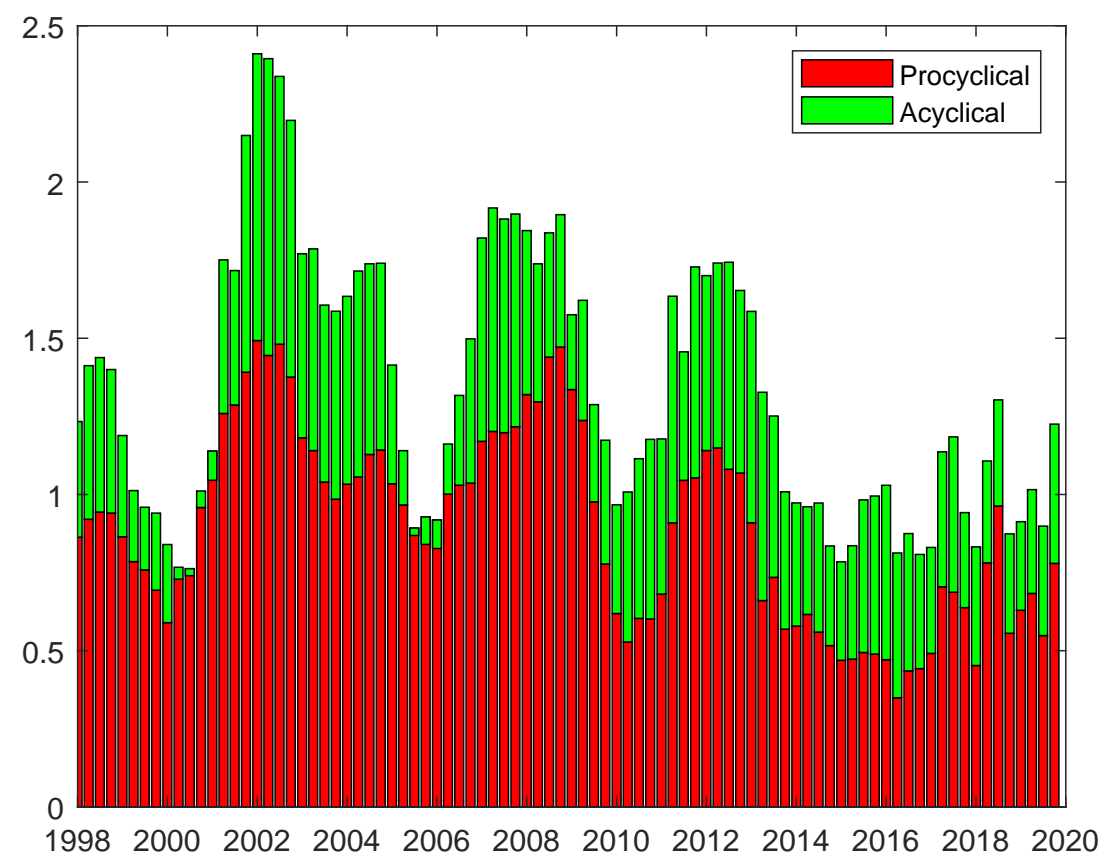

Our results can partially explain why core inflation has remained subdued since 2012, despite the recovery that started in mid-2013 and the expansion of economic activity recorded since then. Indeed, we have shown that there was a lower contribution from

\footnotetext{
${ }^{8}$ The sum of the contributions of the two components is not necessarily perfectly equal to core inflation due to the aggregation issue; for more details on chain-linked decomposition and contribution see (Brunetti, 2010) and (Lutero, 2010).
} 
the procyclical items: their contribution to core inflation is currently smaller than the historical average. More importantly, the procyclical contribution has not increased during the current business cycle, in contrast with the previous expansionary phases. Furthermore, we contribute to the ongoing debate about the possible flattening of the Phillips curve. As price developments in some sectors are not correlated with aggregate cyclical conditions, a Phillips curve type relationship may still hold for some price components while vanishing at the aggregate level. ${ }^{9}$

\section{Common core measure}

In this section, we look at inflation through the lens of a flexible statistical model applied to the cross-sectional distribution of HICP prices that allows the inflation rate to be decomposed into a common and an idiosyncratic component, following the methodology in Conflitti and Luciani (2019) and in Luciani (2020). The proposed measure is similar to the ECB PCCI that technically belongs to the class of generalised dynamic factor models. ${ }^{10}$ In particular, we identify the underlying trend in inflation by removing components that are subject to large or unusual price changes, following the rationale that such idiosyncratic changes are unlikely to be related to the underlying trend of overall and core inflation. We decompose the inflation rate of each items into a common component and an idiosyncratic one. The common component accounts for changes in prices due to shared shocks, and as they are common to all items, we label them "macroeconomic shocks"; the idiosyncratic component accounts for price movements due to non-pervasive shocks, such as sector-specific shocks, regional shocks, and possibly measurement errors.

\footnotetext{
${ }^{9}$ In Section 4 we further assess this issue.

${ }^{10}$ The PCCI can provide some insights into the role of common, low-frequency (i.e. trend) movements across all the 93 components of HICP inflation for 12 countries (ECB (2018), Porqueddu (2018)). The PCCI can be especially useful when several idiosyncratic shocks across countries and items also affect items that are not normally volatile.
} 
Let $\pi_{i t}=1200 \times \log \left(\frac{P_{i t}}{P_{i t-1}}\right)$ be the annualized $m$-o- $m$ log-change in the $i$-th price component at time $t$, where $i=1, \ldots, n$ and $t=1, \ldots, T$, and we have

$$
\pi_{i t}=\boldsymbol{\lambda}_{i}^{\prime} \mathbf{f}_{t}+\xi_{i t}=\chi_{i t}+\xi_{i t}
$$

where $\boldsymbol{\lambda}_{i}$ is a $r \times 1$ vector containing the factor loadings of the $i$-th variable, and $\chi_{i t}=\boldsymbol{\lambda}_{i}^{\prime} \mathbf{f}_{t}$.

11 The factors $\mathbf{f}$ capture common sources of variation in prices; $\epsilon_{i t}$ captures item-specific relative price variability relating to idiosyncratic events. ${ }^{12}$

Under the assumption that all the components - the common factors, the factor loadings, and the idiosyncratic components - are stationary, they can be estimated by the principal components (Stock and Watson (2002), Bai (2003)). Having estimated equation 2 , core inflation can be then decomposed as follows:

$$
\pi_{t, \text { core }}=\sum_{i \in \text { core }} w_{i t} \chi_{i t}+\sum_{i \in \text { core }} w_{i t} \xi_{i t}
$$

where $w_{i t}$ is the HICP weight for item $i$ provided by Eurostat. ${ }^{13}$

\subsection{Results}

We use 93 disaggregate series choosing the 3-digit level of aggregation in the COICOP, starting in 1998 (see the Appendix for the complete list). From this dataset, we remove the following six components that have only been available since January 2000: dental services, hospital services, social protection, other insurance, insurance connected with health, and

\footnotetext{
${ }^{11}$ See for example Cristadoro et al. (2005), Altissimo et al. (2009) and Reis and Watson (2010). As it is standard practice in factor analysis, we have demeaned and standardized all disaggregate prices. A similar approach is used to construct the PCCI.

${ }^{12}$ Common sources of variation in prices may be due to aggregate shocks affecting all sectors (aggregate productivity, government spending an so on); idiosyncratic events can affect some but not all sectors such as for exchange rate fluctuations, weather events in agriculture, and so on

${ }^{13}$ The weights of the COICOP categories are revised yearly and released in February together with the data referring to January.
} 
medical and paramedical services. Eurostat only publishes seasonally adjusted series for the aggregate indexes, so we seasonally adjusted the disaggregated price series ourselves using X12 ARIMA.

Before estimating the model in equation 2 we need to determine the number of factors. Figure 3 shows the largest 20 eigenvalues of the sample correlation matrix of the inflation data; only one of them is outstanding.

Figure 3: SHARE OF VARIANCE EXPLAINED

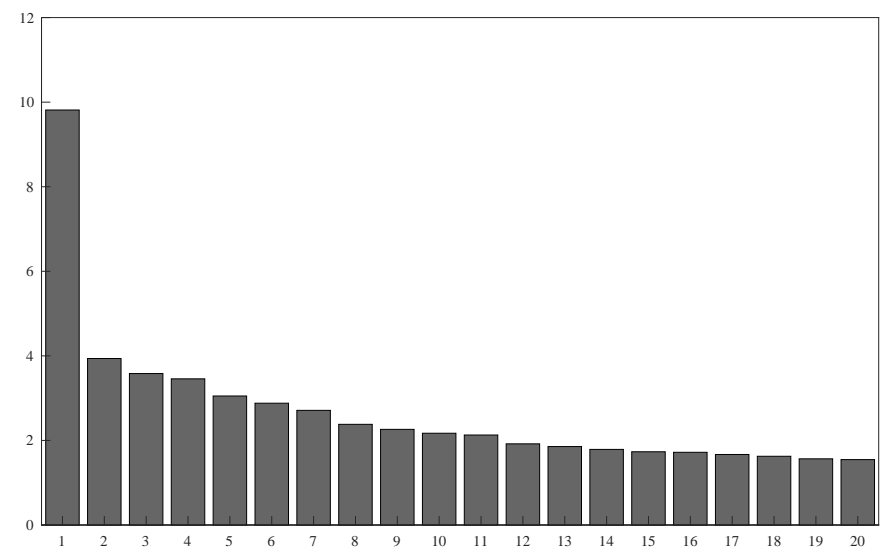

In order to select the number of factors more formally, we use the criterion proposed by Ahn and Horenstein (2013), which is based on the maximization of the ratio of two adjacent eigenvalues: it would confirm the presence of only one factor. Even so, to assess whether the inclusion of more factors is needed we also look at the variance explained by the first three common factors, grouping disaggregated price series into three categories (Figure 4).

The second and the third factors have good explanatory power for the items in the food and energy category, whose dynamics should be plausibly driven to a great extent by idiosyncratic factors (such as weather in the case of food and various supply shocks in the case of energy). For core goods prices, the first and second factors are the most relevant, 
Figure 4: COMmon DyNAMiCS IN HICP PRICES

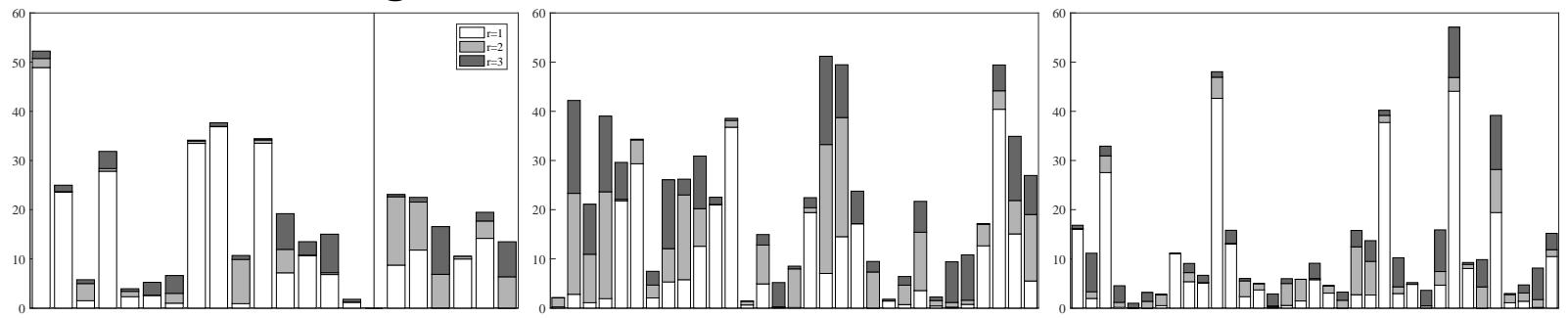

Notes: This figure shows the percentage of variance ( $y$-axis) of each variable ( $x$-axis) explained by the first three factors. Each bar represent a different disaggregate price. The first plot refers to 'Food and energy', the middle plot refers to 'Core goods' and the last plot refers to 'Core services'.

while only the first matters for core services prices. Putting together all this evidence, even if the criterion proposed by Ahn and Horenstein (2013) would allow a conclusion in favour of one factor, our preferred measure of the common component is based on the first two factors. ${ }^{14}$

Figure 5 shows how our measure of the common component for core inflation $\left(\chi^{c}\right)$ compares with the official estimate. Our common component is, as one would expect, smoother than the official index, especially since 2017.

Figure 5: COMMON AND IDIOSYNCRATIC DECOMPOSITION

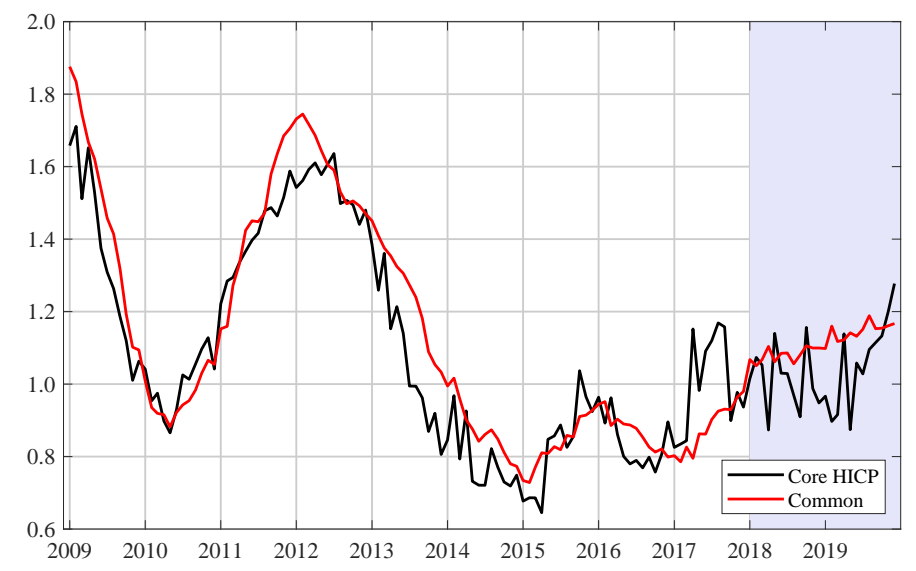

Notes: The red line is the $y-o-y$ common core inflation, the black line is the $y-o-y$ official core inflation.

\footnotetext{
${ }^{14} \mathrm{~A}$ shortcoming of the factor model is the uncertainty about the number of factors to be used. As a robustness check we compute our measure using either one factor or three factors getting similar results.
} 
Figure 6 shows the contributions of our common and idiosyncratic components to official $m-o-m$ inflation rates. Idiosyncratic movements are not negligible and account for a sizable percentage of variance in the $m-o-m$ core inflation rates. Since the beginning of 2018 , the contribution of idiosyncratic components to the $m$-o- $m$ core inflation rates has been mainly negative. From 2013 the negative $m-o-m$ idiosyncratic contributions are mostly related to Easter calendar effects (Figure 6). ${ }^{15}$ The common core component increased in 2017 but has flattened since early 2018, in line with the slowdown in the economic activity in the euro area.

Figure 6: CONTRIBUtions OF COMMON AND IDIOSYNCRATIC COMPONENTS TO CORE INFLATION

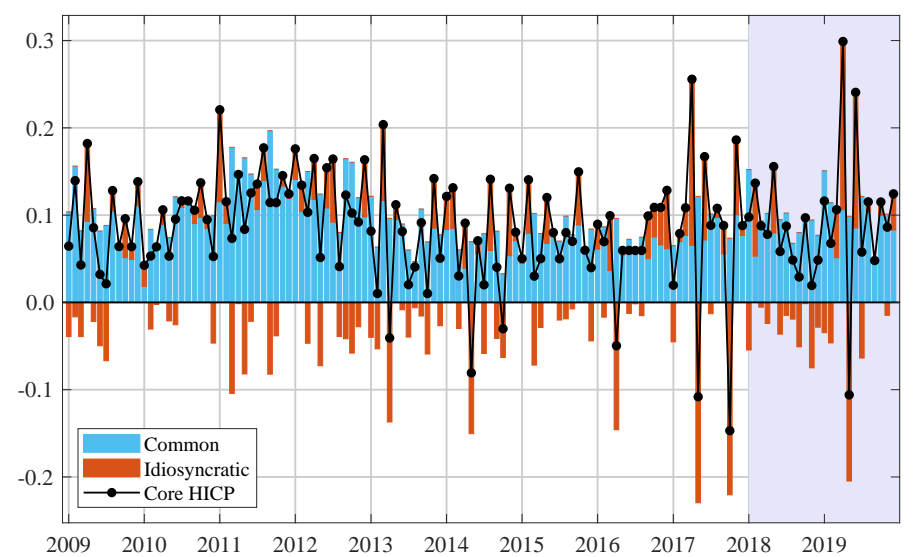

Notes: month-on-month changes; percentage points.

\footnotetext{
${ }^{15}$ Moreover, the $m-o-m$ growth rates of items with advanced technological content are mostly negative. In particular the series: telephone equipment and services, equipment for reception, recording and reproduction of sound and pictures, photographic and cinematographic equipment and optical instruments, and information processing equipment.
} 


\section{A comparison of measures of underlying inflation}

Figure 7 plots all the measures of underlying inflation, namely those proposed here and those proposed by the ECB, as well as official core inflation. All non-official measures are smoother than the official one.

Figure 7: Alternative measures of CORE inflation AND OFFiCiAl CORE INFLATION

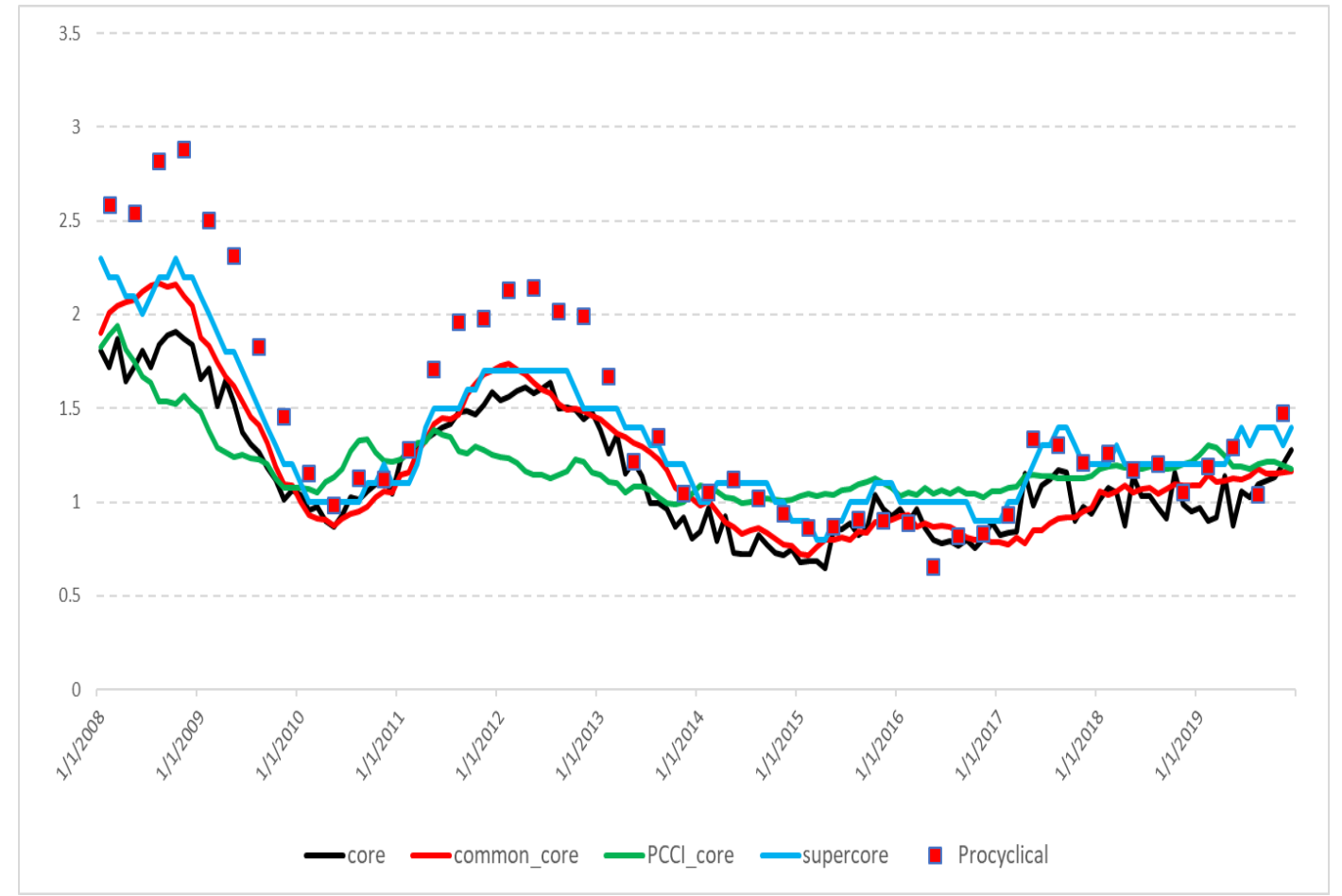

Notes: year-on-year changes; percentage points. For the PCCI and Supercore indicators the data are threemonths moving average annualized as published in the Statistical Data Warehouse. The procyclical indicator is computed using quarterly data.

Our procyclical indicator, which has a quarterly frequency, is often systematically higher than the HICPX ${ }^{16}$. Our common component of core inflation $\left(\chi^{c}\right)$ is the measure that synchronizes best with the HICPX. However, while the former is almost flat at around 1.2

\footnotetext{
${ }^{16}$ It is lower than the HICPX in the last quarter of 2015 and in the first two quarters of 2016.
} 
percent from 2018 onwards, the latter shows a more pronounced volatility. These results suggest that official core inflation has recently been subject to a number of idiosyncratic shocks. The PCCI and the Supercore indicators data are three-months moving average annualized as published by the ECB, therefore they are smoother by construction and this in part alters the comparison as far as volatility is concerned.

Table 1 provides summary statistics for the $y-o-y$ core inflation and other measures over various subsamples (following the analysis proposed in Luciani and Trezzi (2019)). The mean of our common core indicator $\left(\chi^{c}\right)$ is in line with that of core inflation in the whole period (1998-2019) and in the more recent subsample (2009-2019). The results are similar for the Supercore and the PCCI indicator, whose series start later, however, and are published as three-month moving averages, as has been said, which in part alters the comparison as far as volatility is concerned. All measures of underlying inflation filter out some of the volatility in headline inflation. In fact, the standard deviation of the year-on-year rates of change, a crude measure of volatility, is lower for all measures of underlying inflation than for headline inflation (whose volatility stands at 0.9 in the full sample period).

Table 1: Descriptive STATISTICS OF CORE AND UNDERLYing INFLATION MEASURES

\begin{tabular}{l|cc|cc|cc|cc|cc}
\hline \hline & \multicolumn{2}{|c|}{ Core } & \multicolumn{2}{c|}{$\chi^{c}$} & \multicolumn{2}{c|}{ Procyclical ind. } & \multicolumn{2}{c|}{ PCCI } & \multicolumn{2}{c}{ Supercore } \\
\hline Sample & mean & stdev & mean & stdev & mean & stdev & mean & stdev & mean & stdev \\
\hline $1998-2008$ & 1.6 & 0.4 & 1.5 & 0.3 & 2.1 & 0.5 & 1.6 & 0.1 & 2.0 & 0.2 \\
$2009-2019$ & 1.1 & 0.3 & 1.1 & 0.3 & 1.3 & 0.5 & 1.1 & 0.1 & 1.3 & 0.3 \\
$1998-2019$ & 1.3 & 0.4 & 1.3 & 0.4 & 1.7 & 0.6 & 1.3 & 0.2 & 1.5 & 0.4 \\
\hline
\end{tabular}

Notes: Quarterly data for the procyclical core indicator. Supercore data start in March 2003 and are published as three-month moving averages; PCCI data starts in April 2001 and are published as three-month moving average. 


\subsection{How do alternative inflation measures perform in a Phillips curve setting?}

In this subsection we gauge the available measures of underlying inflation based on statistical methods - proposed either in this paper or elsewhere (common core measure and PCCI core) - perform in a Phillips curve (PC) framework. ${ }^{17}$ The relation is specified as follows:

$\pi_{t}=\alpha \pi_{i t-1}+\beta$ EconSlack cl-1 $_{t}+\delta \pi_{t-1}^{e}+u_{t}$, where $\pi_{t}$ is, alternatively, given by one of the following measures of inflation:

- the official core inflation;

- the common component of core inflation $\left(\chi^{c}\right)$;

- the idiosyncratic component of core inflation;

- PCCI core inflation as developed by the ECB.

EconSlack is measured, alternatively, by the unemployment gap or the output gap. $\pi_{t-1}^{e}$ are inflation expectations measured by the Survey of Professional Forecasters (SPF). The PC is estimated on quarterly data from 1998Q1 to 2019Q4 on the $y$-o-y growth rate of inflation.

Table 2 summarizes the results; the proper combination of persistence (which is given by the coefficient of past inflation) and the economic slack coefficients provide the longerterm slope of the PC. The higher the combination of the two, the larger is the cumulative long-run effect of a change in the economic slack measures.

Both economic slack measures are significant for both official core inflation and its common component, but not for its idiosyncratic one. The estimated coefficients of persistence

\footnotetext{
${ }^{17}$ We choose these two maesures because they are both computed with a dynamic factor model. The procyclical indicator and Supercore are not considered here, because they are constructed relying on the PC relationship.
} 
Table 2: Phillips Curve - Core inflation

\begin{tabular}{|c|c|c|c|c|c|c|c|c|}
\hline & Core & Core & $\chi^{c}$ & $\chi^{c}$ & $\xi$ & $\xi$ & 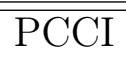 & PCCI \\
\hline$\pi_{i t-1}$ & $0.488^{* * *}$ & $0.502^{* * *}$ & $0.674^{* * *}$ & $0.616^{* * *}$ & $0.444^{* * *}$ & $0.441^{* * *}$ & 0.122 & 0.07 \\
\hline$\pi_{t-1}^{\bar{e}}$ & $\overline{0.48} \overline{1}^{* *}$ & $0 . \overline{4} 36^{\bar{*} *}$ & $\overline{0} . \overline{4} \overline{5}^{-}$ & $\overline{0 .} \overline{27} \overline{3}$ & $\overline{0.14 \overline{7}}$ & $-\overline{0} . \overline{0} \overline{6}$ & $-\overline{6} . \overline{87}$ & $-\overline{1} . \overline{9}$ \\
\hline $\bar{U} G$ & $-0 . \overline{1} 0^{* \bar{*}}$ & & $-\overline{0} . \overline{0} 6^{* \bar{*}}$ & & $0 . \overline{0} 3$ & & $-\overline{1} .0 \overline{2}$ & \\
\hline$\overline{O G}$ & & $\overline{0} . \overline{0} \overline{6} 5^{*}$ & & $\overline{0.06} 3^{* * \bar{*}}$ & & $0 . \overline{00} \overline{9}$ & & $-\overline{8} \overline{7}^{*}$ \\
\hline $\bar{R}^{\overline{2}}$ & $\overline{0.55 \overline{6}}$ & $0.5 \overline{5} \overline{6}$ & $0 . \overline{7} \overline{7}$ & $0 . \overline{80} \overline{5}$ & $0.19 \overline{9}$ & $0 . \overline{19} \overline{5}$ & $\overline{0.01 \overline{9}}$ & $0 . \overline{0} 4 \overline{6}$ \\
\hline
\end{tabular}

Notes: the dependent variable is respectively core inflation, or common core inflation, or idiosyncratic core inflation, or PCCI. Columns differ according to the type of EconSlack variable included among the regressors.

are higher for common core inflation. In the last two columns, we report the results using the PCCI measure: the nexus with economic slack is only statistically significant with the output gap and the estimated coefficients for persistence and inflation expectations are both not significant.

\subsection{Predictive accuracy of measures of underlying inflation}

Finally, an important point to be checked is the predictive accuracy of the measures of underlying inflation, as an indication of the future direction of headline inflation. Hence, we investigate the relative forecasting performance of official core inflation, of the measures that we have here proposed, as well as of those published by the ECB for the headline inflation at one year ahead.

As it can be seen in Tables 3 and 4, which refer to an in-sample and an out-of-sample exercise respectively, the relative performance of the measures of underlying inflation tends to vary over different sub-samples.

In the in-sample exercise, the procyclical core indicator and the Supercore tend to perform best in tracking the benchmark headline inflation, in the post-crisis period, however, this advantage vanishes, though the two measures that we have proposed exhibit the lowest RMSE (Root Mean Square Error). All measures except the procyclical core indicator, tend to have a negative bias (pointing to lower than realised inflation over the whole period). 
As shown in Table 4 , over the full sample and in an out-of-sample setting, the procyclical core indicator is confirmed as the best performer. In the post-crisis sample the conclusions are similar to those stemming from the in-sample exercise, as our measures show the lowest RMSEs but the improvement is not huge.

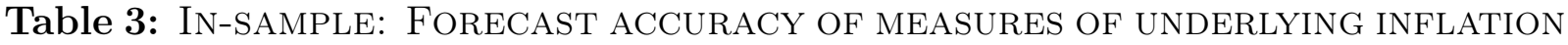

\begin{tabular}{lccccc}
\hline \hline & Core & $\chi^{c}$ & Procyclical ind. & PCCI & Supercore \\
\hline $\begin{array}{l}\text { Full } \\
\text { sample }\end{array}$ & 0.82 & 0.81 & 0.69 & 0.86 & 0.76 \\
RMSE & & & & & \\
\hline $\begin{array}{l}\text { Full } \\
\text { sample }\end{array}$ & -0.31 & -0.36 & 0.06 & -0.35 & -0.10 \\
Bias & & & & & \\
\hline $\begin{array}{l}\text { Post- } \\
\text { crisis }\end{array}$ & 0.84 & 0.82 & 0.80 & 0.89 & 0.83 \\
RMSE & & & & & \\
\hline $\begin{array}{l}\text { Post- } \\
\text { crisis }\end{array}$ & -0.18 & -0.15 & 0.08 & -0.15 & -0.02 \\
BIAS & & & & & \\
\hline
\end{tabular}

Notes: The RMSE is computed by evaluating the error incurred by each of the different measures at each specific time t. Post-crisis: September 2008- December 2019; full sample January 1998- December 2019. 
Table 4: Out-OF-SAmple: Forecast ACCURACY of MeASures of Underlying INFLATION

\begin{tabular}{lccccc}
\hline \hline & Core & $\chi^{c}$ & Procyclical ind. & PCCI & Supercore \\
\hline $\begin{array}{l}\text { Full } \\
\text { sample }\end{array}$ & 0.85 & 0.84 & 0.72 & 0.91 & 0.82 \\
RMSE & & & & & \\
\hline $\begin{array}{l}\text { Full } \\
\text { sample }\end{array}$ & -0.29 & -0.34 & 0.11 & -0.36 & -0.07 \\
Bias & & & & & \\
\hline $\begin{array}{l}\text { Post- } \\
\text { crisis }\end{array}$ & 0.91 & 0.88 & 0.89 & 1.01 & 0.92 \\
RMSE & & & & & \\
\hline $\begin{array}{l}\text { Post- } \\
\text { crisis }\end{array}$ & -0.07 & -0.04 & 0.19 & -0.09 & 0.06 \\
BIAS & & & & & \\
\hline
\end{tabular}

Notes: The RMSE is computed by evaluating the error incurred by each of the different measures at each specific time t. Post-crisis: September 2008- December 2019; full sample January 1998- December 2019. 


\section{Conclusions}

In this work we propose two measures of underlying inflation: a Core cycle measure, that is Phillips curve-based and a Common core measure constructed using a factor model. Our measures are conceptually similar to those used by the ECB and they fit into the debate on the use and monitoring of measures of underlying inflation. These measures are challenged against a number of comparison criteria.

The procyclical indicator is a narrower measure of core inflation that turns out to be more reactive to developments in the real economy; it should be seen as a gauge of cyclical pressures and should be analized together with the acyclical ones to understand the path of inflation. The recent developments in core inflation can be partially explained by the lower contribution of the items that are procyclical: their contribution to core inflation is currently smaller than the historical average. Moreover, it is the best performer in the forecasting evaluations.

The common core indicator $\left(\chi^{c}\right)$ is the measure that synchronizes best with the HICPX and shows a lower volatility with respect to the HICPX. The common core indicator responds to economic slack, while the idiosyncratic component does not. Finally, the predictive accuracy of $\chi^{c}$ is lower than the procyclical indicator but similar to the other measures of underlying inflation proposed by the ECB.

We conclude that none of the measures mentioned stands out with respect to the others, thus recommending that policy makers monitor a wide range of measure to fully assess the behaviour of price dynamics in the medium-term. Our proposed measures provide a picture of broadly similar underlying inflation developments and since each indicator comes with pros and cons, this reinforces the need for monitoring with more than just one measure. 


\section{References}

Ahn, S. C. and A. R. Horenstein (2013). Eigenvalue ratio test for the number of factors. Econometrica 81.

Altissimo, F., B. Mojon, and P. Zaffaroni (2009). Can aggregation explain the persistence of inflation? Journal of Monetary Economics 56, 231-241.

Bai, J. (2003). Inferential theory for factor models of large dimensions. Econometrica 71, $135-171$

Ball, L. M. and S. Mazumder (2019). The nonpuzzling behavior of median inflation. Working Paper 25512, National Bureau of Economic Research.

Brunetti, A. (2010). The decomposition of the chained price index rate of change: generalization and interpretative effectiveness. Rivista di Statistica.

Conflitti, C. and M. Luciani (2019). Oil price pass-through into core inflation. Energy Journal 40, 221-247.

Conti, A. M. (2020). Resurrecting the Phillips curve in low-inflation times. Economic Modelling, forthcoming.

Cristadoro, R., M. Forni, L. Reichlin, and G. Veronese (2005). A core inflation indicator for the euro area. Journal of Money, Credit, and Banking 37, 539-560.

Draghi, M. (2019). Press conference, September 2019.

ECB (2014). The responsiveness of Hicp items to changes in economic slack. Monthly Bullettin September, European Central Bank.

ECB (2018). Measures of underlying inflation for the euro area. Economic Bullettin June, European Central Bank.

Luciani, M. (2020). Common and idiosyncratic inflation. Finance and Economics Discussion Series 2020-024, Board of Governors of the Federal Reserve System.

Luciani, M. and R. Trezzi (2019). Comparing two measures of core inflation:PCE excluding food and energy vs. the trimmed mean PCE index. FEDS Notes August 2, Board of Governors of the Federal Reserve System.

Lutero, G. (2010). The aggregation problem in its historical perspective: a summary overview. Third Wye City Group Global Conference on Agricultural and Rural Household Statistics.

Mahedy, T. and A. Shapiro (2017). What's down with inflation? Economic letters 35, Federal Reserve Bank of San Francisco.

OBrien, D. (2018). The supercore measure of underlying inflation. Box 2 ECB Economic Bullettin 4, European Central Bank.

Porqueddu, M. (2018). The persistent and common component of inflation (PCCI) measure of underlying inflation. Box 3 ECB Economic Bullettin 4, European Central Bank.

Reis, R. and M. W. Watson (2010). Relative goods' prices, pure inflation, and the Phillips correlation. American Economic Journal Macroeconomics 2, 128-157. 
Rostagno, M., C. Altavilla, G. Carboni, W. Lemke, R. Motto, A. Saint Guilhem, and J. Yiangou (2019). A tale of two decades: the ecbs monetary policy at 20. WP series 2346, European Central Bank.

Stock, J. H. and M. W. Watson (2002). Forecasting using principal components from a large number of predictors. Journal of the American Statistical Association 97, 1167-1179.

Yellen, J. (2015). Inflation dynamics and monetary policy. Speech at the Philip Gamble Memorial lecture, University of Massachusetts.

uum 


\section{Appendix A Data}

\section{Appendix A.1 Data for Core cycle measure}

\begin{tabular}{|c|c|c|}
\hline 2-digit E-COICOP & & Euro area \\
\hline 31 & 1 clothing & A \\
\hline 32 & 2 footwear & A \\
\hline 41 & 1 actual rentals for housing & P \\
\hline 43 & 3 maintenance and repair of the dwelling & $\mathrm{P}$ \\
\hline 44 & 4 water supply and miscellaneous services relating to the dwel & A \\
\hline 51 & 1 furniture, furnishing, carpets and other floor covering & P \\
\hline 52 & 2 household textiles & P \\
\hline 53 & 3 household appliances & P \\
\hline 54 & 4 glassware, tableware and household utensils & P \\
\hline 55 & 5 tools and equipment for house and garde & P \\
\hline 56 & goods and services for routine household maintenance & P \\
\hline 61 & 1 medical products, appliances adn equipment & A \\
\hline 62 & 2 out. patient services & $P$ \\
\hline 63 & 3 hospital services & P \\
\hline 71 & 1 purchase of vehicles & A \\
\hline $72^{*}$ & * operation of personal transport and equipment & A \\
\hline 73 & 3 transport services & $\mathrm{P}$ \\
\hline 81 & 1 postal services & A \\
\hline 82 & 2 telephone equipment & A \\
\hline 83 & 3 telephone services & A \\
\hline 91 & 1 audio-visual, photo and information processing equipment & A \\
\hline 92 & 2 other major durables for recreation and culture & A \\
\hline 93 & 3 other recreational items and equipment & $\mathrm{P}$ \\
\hline 94 & 4 recreational and cultural services & $P$ \\
\hline 95 & 5 newspaper, books and stationery & A \\
\hline 96 & 6 package holidays & $P$ \\
\hline 10 & education & A \\
\hline 111 & 1 catering services & $P$ \\
\hline 112 & 2 accomodation services & A \\
\hline 121 & 1 personal care & $P$ \\
\hline 123 & 3 personal effects & A \\
\hline 124 & 4 social protection & A \\
\hline 125 & 5 insurance & A \\
\hline 126 & 6 financial services & A \\
\hline 127 & 7 other services & $\mathrm{P}$ \\
\hline
\end{tabular}

Note: label "P"= procyclical, "A"= acyclical. From item $72 *$ at 2-digit classification series we take out the series 7.2.2 at 3-digit as it refers to "Fuels and lubricants for personal transport equipment" which is not considered as core component as strictly connected to oil prices. 


\section{Appendix A.2 Data for Common core measure}

The price data for the euro area are monthly price indexes for Harmonized Indexes of Consumer Prices (HICP) by type of product taken from the Eurostat website http://appsso. eurostat.ec.europa.eu/nui/show.do?dataset=prc_hicp_midx\&lang=en. In the table belows the column "share" reports the share of variance explained by the common component.

\begin{tabular}{llc}
\hline \hline Name & Label & share \\
\hline Bread and cereals & CP0111 & 48.1 \\
Meat & CP0112 & 28.2 \\
Fish and seafood & CP0113 & 2.6 \\
Milk, cheese and eggs & CP0114 & 27.4 \\
Oils and fats & CP0115 & 0.7 \\
Fruit & CP0116 & 2.7 \\
Vegetables & CP0117 & 1.4 \\
Sugar, jam, honey, chocolate and confectionery & CP0118 & 31.5 \\
Food products n.e.c. & CP0119 & 36.9 \\
Coffee, tea and cocoa & CP0121 & 3.1 \\
Mineral waters, soft drinks, fruit and vegetable juices & CP0122 & 29.5 \\
Spirits & CP0211 & 5.6 \\
Wine & CP0212 & 9.9 \\
Beer & CP0213 & 4.5 \\
Tobacco & CP022 & 2.4 \\
Clothing materials & CP0311 & 0.2 \\
Garments & CP0312 & 2.4 \\
Other articles of clothing and clothing accessories & CP0313 & 0.6 \\
Cleaning, repair and hire of clothing & CP0314 & 17.6 \\
Shoes and other footwear & CP0321-322 & 1.9 \\
Actual rentals paid by tenants & CP0411-412 & 5.0 \\
Materials for the maintenance and repair of the dwelling & CP0431 & 21.2 \\
Services for the maintenance and repair of the dwelling & CP0432 & 31.1 \\
Water supply & CP0441 & 0.0 \\
Refuse collection & CP0442 & 0.9 \\
Sewerage collection & CP0443 & 1.1 \\
Other services relating to the dwelling n.e.c. & CP0444 & 1.4 \\
Electricity & CP0451 & 7.7 \\
Gas & CP0452 & 11.9 \\
Liquid fuels & CP0453 & 0.2 \\
Solid fuels & CP0454 & 10.2 \\
Heat energy & CP0455 & 15.0 \\
Furniture and furnishings & CP0511 & 30.4 \\
Carpets and other floor coverings & CP0512 & 2.8 \\
Repair of furniture, furnishings and floor coverings & CP0513 & 12.1 \\
Household textiles & CP0520 & 5.5 \\
Major household appliances whether electric or not & CP0531-532 & 5.8 \\
Repair of household appliances & CP0533 & 10.6 \\
Glassware, tableware and household utensils & CP0540 & 10.2 \\
Major tools and equip. and small tools and misc. accessories & CP0551-552 & 20.8 \\
\hline & & \\
& & \\
& &
\end{tabular}




\begin{tabular}{|c|c|c|}
\hline Name & Label & share \\
\hline Non-durable household goods & CP0561 & 35.9 \\
\hline Domestic services and household services & CP0562 & 8.6 \\
\hline Pharmaceutical products & CP0611 & 0.0 \\
\hline Other medical products, therapeutic appliances and equipment & CP0612-613 & 6.0 \\
\hline Motor cars & CP0711 & 0.3 \\
\hline Motor cycles, bicycles and animal drawn vehicles & CP0712-714 & 0.1 \\
\hline Spare parts and accessories for personal transport equipment & CP0721 & 17.9 \\
\hline Fuels and lubricants for personal transport equipment & CP0722 & 0.3 \\
\hline Maintenance and repair of personal transport equipment & CP0723 & 42.2 \\
\hline Other services in respect of personal transport equipment & CP0724 & 12.2 \\
\hline Passenger transport by railway & CP0731 & 2.2 \\
\hline Passenger transport by road & CP0732 & 4.0 \\
\hline Passenger transport by air & CP0733 & 0.6 \\
\hline Passenger transport by sea and inland waterway & CP0734 & 0.5 \\
\hline Combined passenger transport & CP0735 & 1.8 \\
\hline Other purchased transport services & CP0736 & 6.2 \\
\hline Postal services & CP081 & 4.3 \\
\hline Telephone and telefax equipment & CP0820-830 & 0.2 \\
\hline $\begin{array}{l}\text { Equipment for the reception, recording and reproduction of sound } \\
\text { and picture }\end{array}$ & CP0911 & 5.8 \\
\hline $\begin{array}{l}\text { Photographic and cinematographic equipment and optical instru- } \\
\text { ments }\end{array}$ & CP0912 & 14.8 \\
\hline Information processing equipment & CP0913 & 19.4 \\
\hline Recording media & CP0914 & 0.0 \\
\hline $\begin{array}{l}\text { Repair of audio-visual, photographic and information processing } \\
\text { equipment }\end{array}$ & CP0915 & 5.3 \\
\hline Major durables for outdoor recreation and indoor recreation & CP0921-922 & 1.0 \\
\hline $\begin{array}{l}\text { Maintenance and repair of other major durables for recreation and } \\
\text { culture }\end{array}$ & CP0923 & 1.4 \\
\hline Games, toys and hobbies & CP0931 & 1.6 \\
\hline Equipment for sport, camping and open-air recreation & CP0932 & 2.8 \\
\hline Gardens, plants and flowers & CP0933 & 0.6 \\
\hline Pets and related products; veterinary and other services for pets & CP0934-935 & 37.7 \\
\hline Recreational and sporting services & CP0941 & 6.6 \\
\hline Cultural services & CP0942 & 6.7 \\
\hline Books & CP0951 & 0.0 \\
\hline Newspapers and periodicals & CP0952 & 0.2 \\
\hline Miscellaneous printed matter;stationery and drawing materials & CP0953-954 & 11.0 \\
\hline Package holidays & CP096 & 0.1 \\
\hline Pre-primary, primary, second., etc, and educ. not def. by level & CP10X0 & 7.5 \\
\hline Restaurants, cafés and the like & CP1111 & 48.2 \\
\hline Canteens & CP1112 & 6.6 \\
\hline Accommodation services & CP112 & 0.0 \\
\hline Hairdressing salons and personal grooming establishments & CP1211 & 25.7 \\
\hline $\begin{array}{l}\text { Electrical appliances for personal care; other appliances, articles and } \\
\text { products for personal care }\end{array}$ & CP1212-1213 & 46.5 \\
\hline Jewellery, clocks and watches & CP1231 & 11.9 \\
\hline Other personal effects & CP1232 & 5.7 \\
\hline Insurance connected with the dwelling & CP1252 & 0.5 \\
\hline Insurance connected with transport & CP1254 & 1.1 \\
\hline Other financial services n.e.c. & CP12622 & 0.5 \\
\hline Other services n.e.c. & CP127 & 14.8 \\
\hline
\end{tabular}

